\title{
Determining the Extent of Territorial Transport Services When Using Rail Transport
}

\author{
Milan Dedík $^{1 *}$, Jozef Gašparík ${ }^{1}$ and Nikolina Brnjac ${ }^{2}$ \\ ${ }^{1}$ University of Žilina, Department of Railway Transport, Univerzitná 8215/1, 01026 Žilina, \\ Slovakia; Email:milan.dedik@fpedas.uniza.sk, jozef.gasparik@fpedas.uniza.sk \\ ${ }^{2}$ University of Zagreb, Faculty of Transport and Traffic Sciences, Vukelićeva 4, 10000 \\ Zagreb, Croatia; Email: brnjac@fpz.hr
}

*Corresponding Author: Milan Dedík

\begin{abstract}
Planning the extent of transport services within a selected territory is a topical issue especially in the context of developing integrated transport systems. The objective of this research study is to design a sustainable system of public passenger transport that would be an alternative to expanding individual transport. The implementation of a quality and efficient transport service is a relatively complex process, since, currently, there are no generally applicable principles for its design. This manuscript presents general results of research aimed at solving the problem of transport service within a selected territory issue with a focus on rail transport as an efficient transport system representing a backbone of a transport system. The subject of the investigation is to compile a set of factors affecting the design of the transport concept. The output of the manuscript consists in a proposal of a generally applicable procedure including a calculation of transport potential and characteristics of the inputs. Subsequently, based on the resulting values, it will be possible to determine the extent of the transport services provided by rail transport in any territory, which will contribute to a more efficient and high quality theoretical graph of train running.
\end{abstract}

Keywords: Public passenger transport, rail transport, extend of transport services, transport capacity

\section{Introduction}

The development of integrated transport systems implies new requirements for transport system functions in terms of serving the selected area. However, currently, there is no methodology focused on an optimal, generally applicable setup of a transport service system in individual transport routes. Rail transport is considered a keystone transport system. 
Creation of a train timetable is based mainly on the current transport lines and frequency of passengers. A part of the research is a proposal of a general methodology for assessing the necessary extent of transport services in a territory on railway lines. Such a complex methodology implies a number of partial inputs to be taken into account as well as determining their importance in identifying the number of trains in a given route or interval between the individual lines [1,2].

\section{Calculation of Transport Capacity as Major Part of Proposed Methodology}

To ensure the optimal extent of transport services and thus increase the attractiveness of the passenger rail passenger, it is necessary to analyse the transport capacity of individual railway lines, or transport routes. Transport capacity refers to the expected volume of passengers transported or the possibility to increase the passenger flow, etc. Based on the analyses results, it would be easier to identify the bottlenecks of these lines or transport routes and subsequently determine the optimal concept of the transport service considering the factors and inputs assessed [3].

For determining the transport capacity, a relationship is proposed that takes into account all the relevant factors affecting it. The main objective is to calculate the value of the overall transport capacity coefficient $K_{p}$, which is determined as a dimensionless coefficient. Its value is directly proportional to the transport capacity. The higher value the coefficient achieves, the higher the capacity of the assessed rail transport route is and requires a transport service concept that would use using the shorter interval rail services. Transport capacity must be monitored for regional and suburban transport as well as long-distance transport or interregional transport, since the transport needs and passengers frequencies are different in different segments. In the presented outline proposal, we will focus on the suburban and regional rail transport only $[4,5]$.

For regional and suburban transport, the $K_{p}$ is calculated as follows:

$$
\mathrm{K}_{\mathrm{p}}=\frac{\mathrm{A} * \mathrm{~K}_{\mathrm{H}} * \mathrm{~K}_{\mathrm{A}}}{\mathrm{L} * \mathrm{D} * \mathrm{~K}_{\mathrm{s}}}[-]
$$

The individual parameters in the calculation are determined and defined as follows:

- $A$ - Average population of all settlements in the monitored area expressed in thousands [-]

Here, the number of inhabitants in the catchment area is given. It is necessary to consider the population of all settlements situated on the monitored transport route. $\boldsymbol{A}$ will thus express the average number of inhabitants in all settlements adjacent to transport points within the railway infrastructure in the monitored area. 
- $K_{H}-$ Mobility coefficient [-]

Here, the mobility coefficient for the relevant area of interest or for the transport route monitored is given. The mobility coefficient expresses the average number of journeys per capita in the monitored period, usually a calendar year. If there is a lack of data, it is possible to use the data on the mobility coefficient at the national level. For example, on the basis of the data on statistical mobility of the inhabitants for all modes of transport in the years 1995, 2000, 2005, 2010, 2014, 2015, 2016 and 2017, the average sum of all journeys of all modes of transport was determined for one Slovak Republic citizen per year and then per day. Subsequently, the average value expressing the number of journeys per capita per for all monitored years was calculated using all the parameters given above. This value was determined as the mobility coefficient $K_{H}$ valid for the Slovak Republic Its value is $K_{H}=1.33$.

- $K_{A}$ - Coefficient of territory attractiveness [-]

The factor of territory attractiveness coefficient $\mathrm{K}_{\mathrm{A}}$ consists of three proposed sub-factors which are expressed by additional coefficients. It is based on the assumption that the attractiveness of a territory is influenced mainly by the number of jobs, the number of institutions for meeting the basic needs of the inhabitants and the number of tourist centres. For exact expression of the sub-factors mentioned above, so-called sub-coefficients are proposed, including the range of their values determined based on an expert estimate:

- Sub-coefficient of settlement size $K_{E}$ - achieves values of 1-6, it is directly proportional to the resulting $\mathrm{K}_{\mathrm{A}}$ value

- Sub-coefficient of tourism $K_{C R}$ - achieves values of 1-4, it is directly proportional to $\mathrm{K}_{\mathrm{A}}$

- Sub-coefficient of unemployment $K_{N}$ - achieves values of 1-4, inversely proportional to $\mathrm{K}_{\mathrm{A}}$

Due to the complexity of the process of determining the value range for the individual subcoefficient, it will not be mentioned here in detail. The resulting formula for calculating $\mathrm{K}_{\mathrm{A}}$ is as follows:

$$
\mathrm{K}_{\mathrm{A}}=\frac{\mathrm{K}_{\mathrm{E}} * \mathrm{~K}_{\mathrm{CR}}}{\mathrm{K}_{\mathrm{N}}}[-]
$$

- $L$ - Average transport distance between the individual transport points in the monitored area $[\mathrm{km}]$

Due to the required exactness of the result, it is necessary to determine the transport distance factor between each pair of adjacent points on the monitored transport route, since these distances affect the value of the overall transport capacity. The resulting value $\mathrm{L}$ represents the average of all the distances. 
- $\quad D$ - Average accessibility of a tariff point on the railway line - its distance from the centre of the adjacent settlement $[\mathrm{km}]$

In order to simplify the monitoring of the accessibility factor within the methodology proposed, it would be more effective to consider the distance of the railway station or stop only from the centre of the given settlement, which would express their accessibility. In the case of more tariff points, it would be necessary to consider their distance to the selected destinations (in this case, this would apply mainly to housing estates and industrial areas). The resulting value of the railway station or stop accessibility would represent the average value of all these distances.

- $K_{S}-$ Coefficient of overlap with road [-]

The coefficient $K_{S}$, is proposed as a ration of the travel time within the railway infrastructure $t_{j_{\check{Z ̆ D}}}$ and the travel time spent travelling using regular bus lines $t_{j_{C D}}$. It is calculated as follows:

$$
\mathrm{K}_{\mathrm{S}}=\frac{\mathrm{t}_{\mathrm{j}_{\mathrm{Z̆D}}}}{\mathrm{t}_{\mathrm{j}_{\mathrm{CD}}}}[-]
$$

The higher the value of $t_{j_{\check{Z} D}}$ is compared to the value of $t_{j_{C D}}$, the higher the value of $K_{S}$ is, and the less favourable it is for railway transport. This coefficient considers the overall travel time on the reference route ensured by train lines compared to the overall travel time spend travelling by regular bus services.

\section{Determining the Extent of Transport Services Based on Transport Capacity}

Following the determination of the resulting value of the transport capacity coefficient $K_{p}$, it is necessary to convert this value into the number of trains or interval between the lines, and the number of seats on train per certain interval. This would create an offer and thus a transportation concept on the monitored transportation route.

The benefit of the proposed approach would be determination of approximate frequencies of daily passenger flow on weekdays and weekends on the basis of the calculated transport capacity on a given route. However, the relationships between the individual input factors are very complex. On their basis it would be suitable to determine expected frequency of passengers on the monitored transportation route. This would serve as a basis for determining the necessary number of trains and seating capacity. Using a simplified procedure, it would be possible to use the current frequency of passengers in individual sections. Nevertheless, such values can be distorting as they are strongly influenced by the current extent of the transport services [6]. 
After considering various procedures to carry out this transformation, the following one was chosen:

- On a simplified model of a line (transport route), model values will be assigned to individual factors,

- The model calculation of $K_{p}$ will be carried out in two extreme cases,

- Extreme cases include determining the resulting value of $\mathrm{K}_{\mathrm{p}}$ within the transport services extent I (extreme case 1) and transport services extent VIII (extreme case 2),

- For calculating the extreme value of the transport service extent I $K_{\mathrm{p}}$, model values of the individual parameters will be chosen which are threshold for the attractiveness of railway passenger transport within the monitored area. On the basis of expert and scientific consultations with wide expert public, a model railway line $A-G$ was designed for these purposes (the transport point $\mathrm{X}$ represents the number of inhabitants in other settlements adjacent to the monitored railway line), with highlighted input values and the following calculations:

Table 1 Model calculation of Kp on model railway line A - G. Source: authors

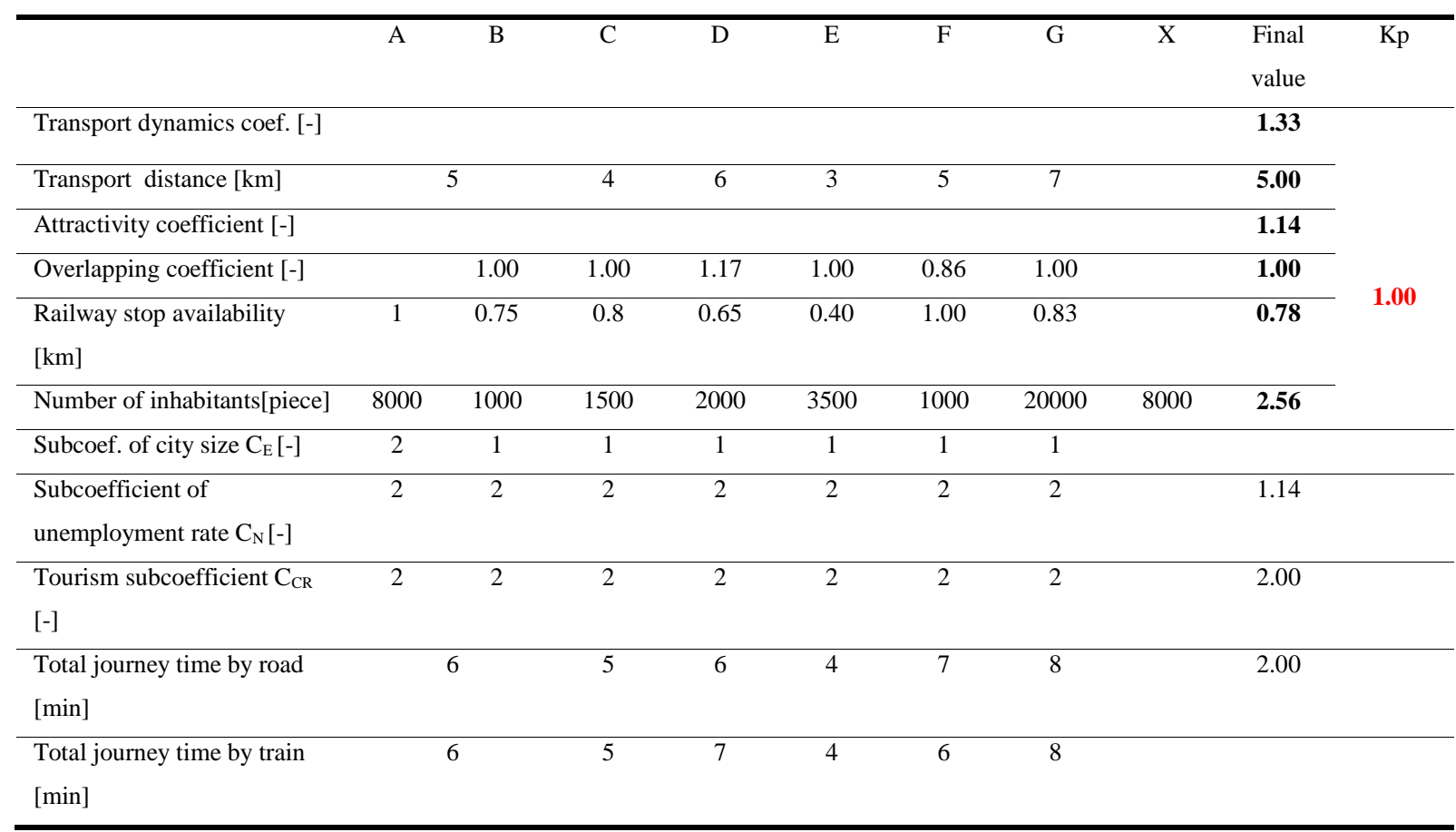

- A total of eight extents (degrees) of transport service are proposed (I - VIII),

- The resulting value $K_{p}=1.00$ will be the upper limit value for the transport service extent I; however, considering the principle of railway transport sustainability, the extent of the railway passenger transport I, or the minimum transport service extent is 
recommended to be used also for railway lines and transport routes with the value lower than 1.00;

- The value $\mathrm{K}_{\mathrm{p}}$ for the transport service extent VIII will be calculated in the same way, except that there will be chosen model values of individual parameters, which maximize the attractiveness of the railway passenger transport and can represent the extreme case 2. On the basis of expert and scientific consultations with expert public, the following model values and calculations on the railway line A - G were proposed for these purposes:

Table 2 Calculation of Kp on model railway line A - G with changed input data. Source: authors

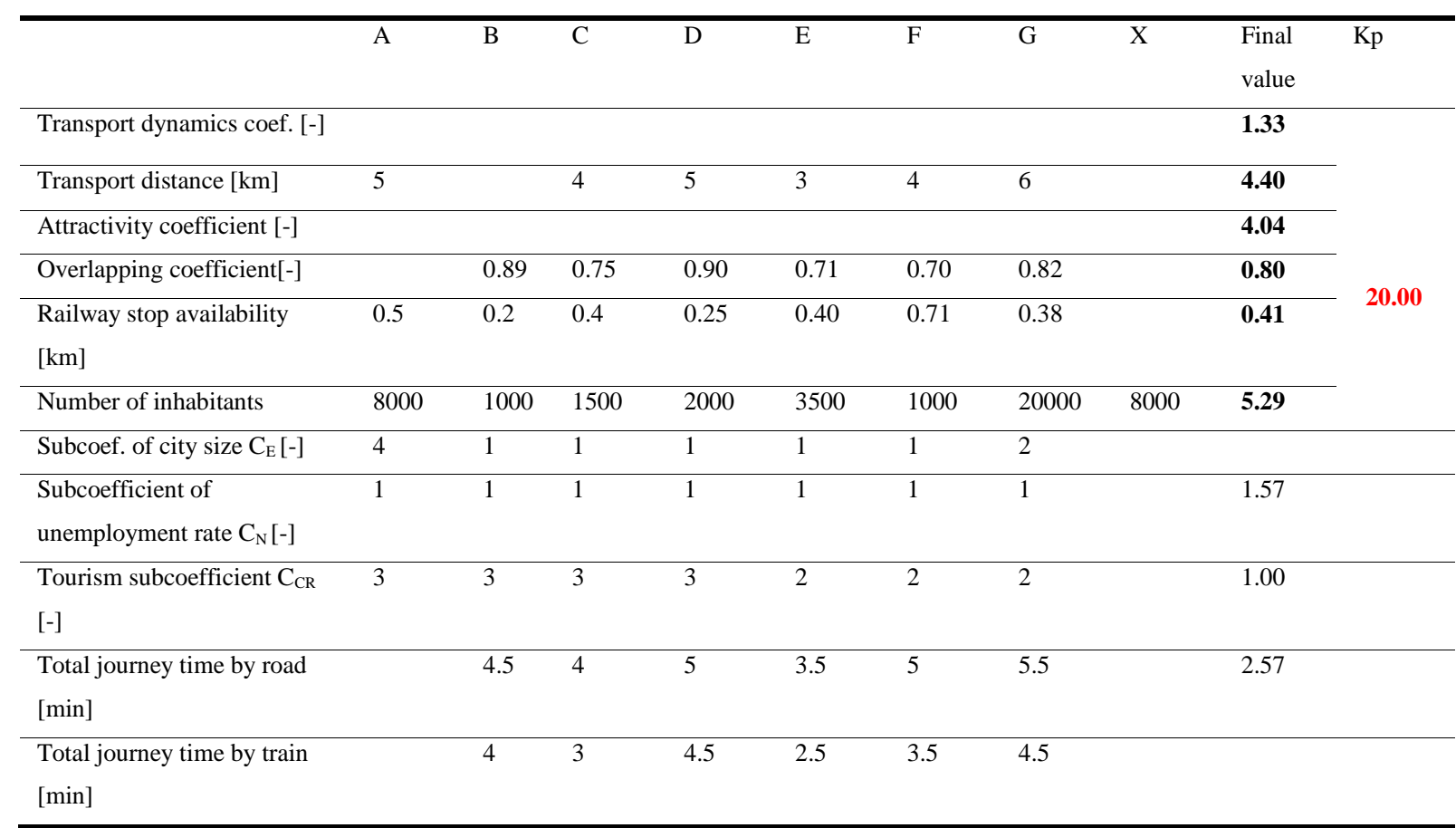

- The resulting value $\mathrm{K}_{\mathrm{p}}=20.00$ will be the upper limit value for the transport service extent VII, while all higher values will fall under the transport service extent VIII;

- Subsequently, based on the calculated extreme values, the scale and assignment of the resulting values to individual transport service extents (I - VIII) including the determination of the optimal number of trains and optimal number of seats and operating mode of the trains on the monitored route;

- For shorter distance transport, or in the case of regional and suburban transport, the values given in Tab. 3 are recommended. The characteristics of the recommended extent (degree) of operation are given below the table. 
Table 3 Parameters of individual transport service extents. Source: authors

\begin{tabular}{cccc}
\hline $\begin{array}{c}\text { Transport } \\
\text { service } \\
\text { extent }\end{array}$ & $\begin{array}{c}\text { Range of transport } \\
\text { capacity } \\
\mathrm{K}_{\mathrm{p}}[-]\end{array}$ & $\begin{array}{c}\text { Optimal number of all } \\
\text { passenger trains pairs }\end{array}$ & $\begin{array}{c}\text { Optimal number of seats in all } \\
\text { trains in both directions }\end{array}$ \\
\hline I & $0-1-00$ & 4 & Up to 500 \\
\hline II & $1-01-2-00$ & $5-6$ & $501-1000$ \\
\hline III & $2-01-3-00$ & $7-10$ & $1001-2000$ \\
\hline IV & $3-01-5-00$ & $11-15$ & $2001-5000$ \\
\hline V & $5-01-10-00$ & $16-20$ & $5001-10000$ \\
\hline VI & $10-01-15-00$ & $21-25$ & $10001-15000$ \\
\hline VII & $15-01-20-00$ & $26-30$ & $15001-20000$ \\
\hline VIII & $20-01$ and more & 31 and more & 20001 and more \\
\hline
\end{tabular}

- Extent I - The minimum transport service, which is 4 pairs of passenger trains usually during the peak times. Here it is necessary to reassess the effectiveness of the train lines;

- Extent II - Lines preferably used at peak hours. A clock-face schedule is possible;

- Extent III - Lines shall be operated during the whole day considering the higher number of lines at peak hours. A clock-face schedule is possible;

- Extent IV - Lines shall be operated at two-hour intervals during the whole day and one-hour intervals at peak hours;

- Extent V - Lines shall be operated at one-hour intervals during the whole day, with possible omitting of a certain hour at the off-peak hour;

- Extent VI - Lines shall be operated at one-hour intervals during the whole day, with switching to 30-minute intervals at peak hours;

- Extent VII - Lines shall be operated at 30-minute intervals during the whole day except for morning and evening off-peak hours, where one-hour intervals will be used;

- Extent VIII - Lines shall be operated at 30-minute intervals during the whole day with a switch to 20-, 15-, or 10-minute interval at peak hours $[7,8]$.

\section{Brief Practical Application of the Proposed Methodology}

Based on the methodology described above, a particular case study was elaborated, in which the transport capacity was calculated, and subsequently, the transport service extent on six transport routes of the Railways of the Slovak Republic network was determined. The data is given in the table below [9-11]. 
Table 4 Application of proposed methodology on six transport routes. Source authors

\begin{tabular}{ccc}
\hline Transport route & $\begin{array}{c}\text { Resulting Kp } \\
\text { value }\end{array}$ & $\begin{array}{c}\text { Resulting extent of transport } \\
\text { services }\end{array}$ \\
\hline Bratislava - Galanta & 26.34 & VIII \\
\hline Trenčín - Chynorany & 2.87 & III \\
\hline Nové Mesto n/V - Velká n. V. & 2.6 & III \\
\hline Nemšová - Lednické Rovne & 1.81 & II \\
\hline Žilina - Rajec & 5.91 & V \\
\hline Bánovce n/B - Vel'ké Kapušany & 0.46 & I \\
\hline
\end{tabular}

It results from the calculations that the highest transport capacity is on the route Bratislava - Galanta, where the transport service extent VIII is considered. Based on the data in the table, this represents more than 31 pairs of lines with the seating capacity of more than 20000 seats. Conversely, the lowest transport capacity show the route Bánovce n/B - Vel'ké Kapušany, where the transport service extent I is considered, which equals to 4 pairs of lines per day, with a seating capacity of up to 500 seats.

\section{Conclusion}

The presented design for assessing the necessary extent of transport service on railway routes was compiled with regard to the factors identified which significantly influence the demand for regional railway transport.

Within the proposal, the calculation method for determining the transport capacity including the individual input values was analysed. Subsequently, based on the model values, a scale was created for eight types of possible transport service extent. The result obtained is the railway transport concept on a selected transport route in the context of providing transport services in the region. However, the process is quite complicated, and it was not possible to include all sub steps. Further procedures and proposals within the methodology will be the subject of further research. In principle, practical application of the proposed methodology may contribute significantly to determining the optimal concept of transport service and assessing the effectiveness of suing regional railway lines in integrated transport systems,

\section{Acknowledgement}

The contribution was written within the framework of the gran project VEGA 1/0509/19 "Optimizing the use of railway infrastructure with support of modal split forecasting" that is solved at Faculty of Operations and Economics of Transport and Communication, University of Žilina. 


\section{References}

[1] Strategy of the development of public passenger and non-motorized transport of the Slovak Republic until 2020. (2014). Bratislava, Ministry of Transport, Construction and Regional Development of the Slovak Republic.

[2] Ministry of Transport, Construction and Regional Development of the Slovak Republic. (2017). Public Passenger transport 2030 (Verejná osobná doprava 2030), 90 p.

[3] Zitrický, V., Ponický, J. \& Černá, L. (2017) Conditions of the creation an integrated transport system. Roads and Railways (Pozemné komunikácie a dráhy). 13(1), p. 45-50. ISSN 1336-7501.

[4] Meško, P., Zitrický, V. \& Záhumenská, Z. (2017). The proposal of regional transport service on selected track section. In Transport in Košice region to 2020: the 3rd International Conference. 2017, 67-73. ISBN 978-80-971246-6-3.

[5] Zavada, J. Abramovic, B. \& Sipus, D. (2017). A Strategic model of sustainable mobility in the city of Zagreb and its surrounding area. Int. J. Traffic \& Transport Engineering. 7(4).

[6] Kuník, P. (2012). The Proposal of the Integrated Cycle Time Table in Slovakia in 2012. Diploma thesis, University of Pardubice, Czech Republic, 91 p.

[7] Dedík, M, Dlugoš, M, Gašparík, J, Lupták, V \& Blaho, P. (2017). Optimization of empirical models of transport planning in railway transport. Transport and communications: Scientific Journal. 5(2), 1-5.

[8] Majerčák, J., Kudláč, Š. \& Ponický, J. (2016). Innovative management of supply chains. Logi - Scientificc journal on transport and logistics. 7(1), 98-107. ISSN 1804-3216.

[9] Mašek, J., Kendra, M. \& Čamaj, J. (2016). Model of the transport capacity of the train and railway track based on used types of wagons. In Transport means - Proceedings of the 20th international conference. 5-7 October 2016 (pp. 584-588). Kaunas, Lithuania.

[10] Široký, J., Cempírek, V., Gašparík, J., Nedeliaková, E., Pivoňka, K., Seidlová, A. \& Císařová, H. (2009). Technologie dopravy. Pardubice, Institute of Jan Perner, Czech Republic. ISBN 978-80-86530-53-6. (in Czech)

[11] Stojadinović, N., Bošković, B., Trifunović, D. \& Janković, S. (2019). Train path congestion management: Using hybrid auctions for decentralized railway capacity allocation. Transportation Research Part A: Policy and Practice. 129, 123-139. DOI: 10.1016/j.tra.2019.08.013. 